\title{
BMJ Open Associations of household food insufficiency with childhood depression and anxiety: a nationwide cross- sectional study in the USA
}

\author{
Siwen Zheng, ${ }^{1}$ Amanda L Ngo, ${ }^{2}$ Michele R Forman, ${ }^{3}$ Anna L Barcellos, ${ }^{1}$ \\ Lauren Liao, ${ }^{1}$ Assiamira Ferrara, ${ }^{2}$ Yeyi Zhu (D) ${ }^{2,4}$
}

To cite: Zheng S, Ngo AL, Forman MR, et al. Associations of household food insufficiency with childhood depression and anxiety: a nationwide cross-sectional study in the USA. BMJ Open 2021;11:e054263. doi:10.1136/ bmjopen-2021-054263

\section{- Prepublication history and} additional supplemental material for this paper are available online. To view these files, please visit the journal online (http://dx.doi.org/10.1136/ bmjopen-2021-054263).

Received 07 June 2021 Accepted 17 August 2021

\section{Check for updates}

(c) Author(s) (or their employer(s)) 2021. Re-use permitted under CC BY-NC. No commercial re-use. See rights and permissions. Published by BMJ.

${ }^{1}$ School of Public Health, University of California Berkeley, Berkeley, California, USA ${ }^{2}$ Division of Research, Kaiser Permanente Northern California, Oakland, California, USA ${ }^{3}$ Department of Nutrition Science, Purdue University, West Lafayette, Indiana, USA

${ }^{4}$ Department of Epidemiology and Biostatistics, University of California San Francisco, San Francisco, California, USA

Correspondence to Dr Yeyi Zhu; Yeyi.Zhu@kp.org

\section{ABSTRACT}

Objective Household food insufficiency (HFIS) is a major public health threat to children. Children may be particularly vulnerable to HFIS as a psychological stressor due to their rapid growth and accelerated behavioural and cognitive states, whereas data focusing on HFIS and childhood mental disorders are as-yet sparse. We aimed to examine the associations of HFIS with depression and anxiety in US children.

Design Cross-sectional study.

Setting The 2016-2018 National Survey of Children's Health, a nationally-representative study.

Participants Primary caregivers of 102341 children in the USA.

Primary and secondary outcome measures Physician diagnosed depression and anxiety were assessed by questionnaires administered to primary caregivers of 102 341 children. Multivariable logistic regression models estimated adjusted OR (aOR) for current depression or anxiety associated with HFIS measured through a validated single-item instrument.

Results Among children aged 3-17 years, 3.2\% and $7.4 \%$ had parent-reported physician-diagnosed current depression and anxiety, respectively. Compared with children without HFIS, children with HFIS had approximately twofold higher weighted prevalence of anxiety or depression. After adjusting for covariates, children with versus without HFIS had a 1.53 -fold $(95 \%$ Cl 1.15 to 2.03 ) and 1.48-fold (95\% Cl 1.20 to 1.82$)$ increased odds of current depression and anxiety, respectively. Associations were slightly more pronounced among girls (aOR $(95 \% \mathrm{Cl})$ : depression 1.69 (1.16 to 2.48); anxiety 1.78 (1.33 to 2.38$)$ ) than boys (1.42 (0.98 to 2.08); 1.32 (1.00 to 1.73); both P-for-interaction $<0.01$ ). The associations did not vary by children's age or race/ ethnicity.

Conclusions HFIS was independently associated with depression and anxiety among US children. Girls presented slightly greater vulnerability to HFIS in terms of impaired mental health. Children identified as food-insufficient may warrant mental health assessment and possible intervention. Assessment of HFIS among children with impaired mental health is also warranted. Our findings also highlight the importance of promptly addressing HFIS with referral to appropriate resources and inform its potential to alleviate childhood mental health issues.
Strengths and limitations of this study

- Our study is among the first large-scale investigation of household food insufficiency and childhood depression or anxiety using a contemporary nationwide, multiracial/multiethnic sample of children aged 3-17 years in the USA.

- The National Survey of Children's Health sampling weights allow us to account for complex survey design and potential non-response bias.

- Our study includes robust data on a comprehensive set of covariates to minimise potential residual confounding.

- Our study was based on a cross-sectional nationwide survey, without the ability to differentiate antecedents from endpoints and thereby infer causality between household food insufficiency and childhood depression or anxiety.

\section{INTRODUCTION}

Household food insecurity, defined as limited access or availability to nutritionally adequate food, is a major public health burden to children. In 2018, $15.2 \%$ (11.2 million) of US children lived in food-insecure households. ${ }^{1}$ Mental disorders are another critical threat to children and are the leading condition for healthcare expenditure in children, totalling $\$ 13.9$ billion for treatment of mental disorders in US children in $2012 .^{2}$ In the past decade, there has been an upward trend in the prevalence of depression and anxiety especially in adolescents. ${ }^{3-5}$ Indeed, childhood depression and anxiety are of particular public health concern due to the adverse and long-lasting impact by interfering with children's cognitive, emotional and social development, which may even lead to substance abuse and suicide.$^{6-8}$ Finally, children may be particularly vulnerable to food insecurity as a psychosocial stressor during this dynamic life stage of rapid growth and development. 
Previous research has primarily focused on the impact of household food insecurity on child physical health, ${ }^{9-11}$ with relatively fewer data on cognitive development. ${ }^{12}$ Prior studies have linked household food insecurity to an array of childhood cognitive development issues ranging from poor school performance to suicide ideation, ${ }^{13-20}$ with limited data on depression or anxiety as primary mental disorder outcomes. ${ }^{17-20}$ Importantly, inferences from these studies have been largely hampered by restricted geographical and racial/ethnic variations, inconsistent definitions of mental health status and residual confounding due to missing covariates including child's health insurance, household factors and parental mental health. Contemporary data on food insecurity in relation to depression or anxiety among children of diverse geographical and racial/ethnic groups with comprehensive assessment of important risk factors in the US are lacking.

Further, more women than men were susceptible to food insecurity related depression and anxiety due in part to sex differences in biological, cultural and experiential factors, ${ }^{21}{ }^{22}$ whereas sex-specific associations of food insecurity with depression and anxiety among children remain elusive. Moreover, given the previously reported age and racial/ethnic differences in risk of childhood depression and anxiety ${ }^{23-25}$ and that food insecurity tends to disproportionally impact more racial/ethnic minorities, ${ }^{26} 27$ examination of potential effect modification by child's age and race/ethnicity may inform risk-based preventive or intervention strategies.

The ongoing coronavirus disease 2019 (COVID-19) pandemic has the potential of posing a dual-threat of increased food insecurity and depression or anxiety in children. Since the pandemic, the number of children who experience household food insecurity has rapidly increased, with an unprecedented 18 million in $2020{ }^{28}$ Simultaneously, depression and anxiety rates have increased among various populations including children. ${ }^{29-31}$ Therefore, investigation of the association of food insecurity with childhood depression and anxiety is warranted to determine whether there is an association and if so, to inform timely preventive and intervention efforts to mitigate children's psychosocial stress.

While household food insecurity indicates limited access or availability to nutritionally adequate food, household food insufficiency (HFIS) suggests an inadequate amount of food intake due to a lack of money or resources. ${ }^{32}$ The latter has been used as a synonym for hunger and is a more severe form of the former, which has been understudied. ${ }^{33}$ Therefore, to address the above-mentioned gaps in the literature, in a nationally representative sample of children aged 3-17 years in the US, we examined these association of HFIS with current depression and anxiety and examined whether these associations may vary by children's age, sex or race/ ethnicity.

\section{METHODS}

\section{Study sample and design}

Data were drawn from the 2016-2018 National Survey of Children's Health (NSCH), a nationally representative, parent/caregiver-completed cross-sectional survey among US children under 18 years old. Detailed methodology of the survey was previously described elsewhere. ${ }^{34}{ }^{35}$ In brief, households were selected based on child-presence flags provided by the Census Master Address File, with $60 \%$ addresses from Stratum 1 (flagged as households with children) and $40 \%$ from Stratum 2a (not flagged but has a higher probability of child presence than Stratum 2b), in order to improve sampling efficiency. ${ }^{36}$ The selected households were contacted by mail to identify those with at least one child under 18 years old, among whom one child was randomly selected per household for parental/caregiver's response to the survey. ${ }^{37}$ The household adult who was most familiar with the child's health status completed the survey via web or paper in English or Spanish. In total, 102341 responses were collected in 2016-2018, of which 50 212, 21599 and 30530 were completed in these 3 years, respectively.

Among 102341 children, we first excluded children less than 3 years old given the low prevalence of infant depression and anxiety $(n=13$ 829). We further excluded children with missing or invalid data on HFIS $(n=1694)$ or parent-reported physician-diagnosed outcomes of interest ( $\mathrm{n}=391$ for depression and $\mathrm{n}=526$ for anxiety). The final analytical sample comprised 86427 children for depression and 86292 children for anxiety (see study flowchart in figure 1). Children in the analytical sample, compared with those excluded due to missing or invalid data on HFIS and depression or anxiety, did not differ by sex but were slightly more likely to be non-Hispanic white, enrol in private health insurance, have less severe household poverty status, live in a family with two married parents and have a parent/caregiver with good mental/ emotional health status (online supplemental table 1).

\section{HFIS measurement}

The 2016-2018 NSCH employed a single-item instrument to assess HFIS as used previously. ${ }^{38-40}$ The primary caregiver was asked, 'Which of these statements best describes the food situation in your household IN THE PAST 12 MONTHS?', with four choices: ' $1=$ We could always afford to eat good nutritious meals; $2=$ We could always afford enough to eat but not always the kinds of food we should eat; 3=Sometimes; and $4=$ Often we could not afford enough to eat'. A positive answer to 3 or 4 was deemed HFIS as done previously. ${ }^{41}$ Single-item instrument for HFIS have been previously validated and used as a proxy for household food insecurity in the National Health and Nutrition Examination Survey. ${ }^{42-44}$

\section{Outcome measure}

The respondents were asked, 'Has a doctor or other health care provider EVER told you that this child has depression or anxiety problems?', 'If yes, does this child 


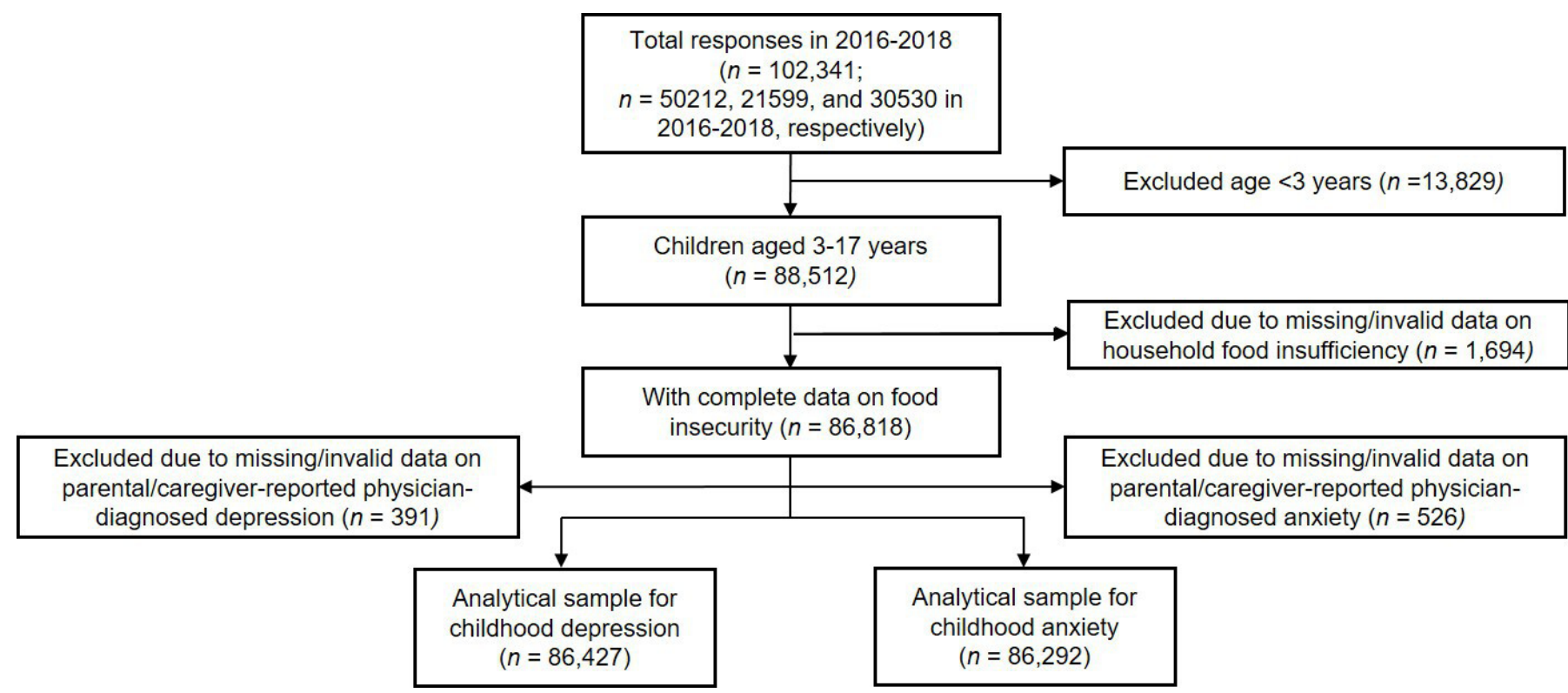

Figure 1 Study flowchart with unweighted survey sample sizes for children aged 3-17 years, National Survey of Children's Health, 2016-2018.

CURRENTLY have the condition?'. The child was considered to have physician diagnosis of current depression or anxiety if the respondent reported 'Yes' to both the first and second questions and have no current depression or anxiety if the respondent reported 'No' to the second question.

\section{Covariates}

Potential covariates were selected based on biological plausibility, prior knowledge and statistical considerations, including: child's age (3-5, 6-11, 12-17 years), sex (boys, girls), race/ethnicity (Hispanic, non-Hispanic white, non-Hispanic black, other), health insurance type (any public, private only, missing/uninsured), household poverty status $(0-99,100-199,200-399, \geq 400$ per cent of federal poverty level, an economic measure used to decide whether a household would be eligible to receive welfare benefits, ${ }^{45}$ with a lower percentage meaning more likely to live in poverty), family structure (two parents, married; two parents, unmarried; single parent or other (ie, grandparent or other relation)), parental/primary caregiver's mental/emotional health status (fair or poor, good, very good or excellent), and geographical region (Midwest, Northeast, South, West). Further, given the potential role of obesity in childhood depression and anxiety ${ }^{46}$ we additionally adjusted for child's body mass index (BMI) in a secondary analysis. Data on BMI were only available among children aged 10-17 years in the NSCH given the reasonably high classification rate $(97.5 \%)$ of obesity status based on parent-reported weight and height among older school-aged children but not preschool or elementary school-aged children. ${ }^{47} 48$ A covariate was included in the final model if the coefficient of exposure of interest changes by $10 \%$ or more. $^{49}$

\section{Statistical analysis}

The NSCH sampling weights were applied to all analyses, accounting for the complex survey design and potential non-response bias. ${ }^{50}$ The sampling weights were developed from base sampling weights which were the inverse of the probability of the selection of the address, and further adjusted for non-response, within-household subsampling factors. ${ }^{51}$ Unweighted number and weighted prevalence of current depression or anxiety were calculated. The Rao-Scott $\chi^{2}$ test was used to obtain $p$ values for group comparisons of categorical variables. ${ }^{52}$

Univariable and multivariable logistic regressions assessed the associations of HFIS with parent-reported physician diagnosis of childhood depression or anxiety, respectively. Of note, two multivariable logistic regression models (Models 1 and 2) were performed, one adjusting for child's and household covariates, and the other additionally adjusting for parental or primary caregiver's mental and emotional health status. This was based on the fact that many previous studies did not adjust for or have data on parental or primary caregiver's mental and emotional health status and we would like to examine how this covariate could potentially affect the associations of HFIS with parent-reported physician diagnosis of childhood depression or anxiety. Given the relatively low prevalence of depression or anxiety in children aged 3-5 years, we conducted a sensitivity analysis restricted to children aged 6-17 years. Given the potential role of child's obesity in risk of depression and anxiety, ${ }^{46} 53-56$ we performed another sensitivity analysis additionally adjusting for child's BMI among children aged 10-17 years to test the robustness of findings. Notably, child's BMI data were only available among this elder age group in the NSCH. Further, due to the potentially bi-directional association between childhood obesity and mental 
disorders and the cross-sectional nature of this study, we acknowledge that this is simply an exploratory analysis.

Further, we tested for an interaction between HFIS and child's sex, age and race/ethnicity by including a cross product term and conducted stratified analysis by these factors, respectively. The P-for-interaction was calculated using the likelihood ratio test. All analyses were performed using SAS V.9.4 (SAS Institute) and the statistically significant level was set at a two-tailed value $<0.05$.

\section{Patient and public involvement}

Patients or the public were not involved in the design, or conduct, or reporting, or dissemination of this research.

\section{RESULTS}

Among US children aged 3-17 years from the 2016-2018 NSCH, 3.2\% (weighted estimate 1.9 million) and $7.4 \%$ (4.4 million) had parent-reported physician-diagnosed current depression and anxiety, respectively (table 1). The weighted prevalence of depression was $8.2 \%$ in children exposed to HFIS versus $2.9 \%$ in children non-exposed to HFIS $(p<0.001)$. The weighted prevalence of anxiety was $13.9 \%$ in children exposed to HFIS versus $7.0 \%$ in children non-exposed to HFIS $(\mathrm{p}<0.001)$. Overall, the weighted prevalence of depression was higher among children who were: aged $\geq 12$ years, girls, non-Hispanic black and nonHispanic white, in single-parent households or households with other than two parents, in poverty, enrolled in public insurance, with a parent or primary caregiver that had impaired mental and emotional health (all $\mathrm{p}<0.001)$; and those resided in the Midwest of USA (both $\mathrm{p}<0.005$ ). The weighted prevalence of anxiety was higher among children who were: aged $\geq 12$ years, non-Hispanic white, in single-parent households or households with other than two parents, enrolled in public insurance, with a parent or primary caregiver that had impaired mental and emotional health, resided in the Midwest of USA (all $\mathrm{p}<0.001)$; and girls $(\mathrm{p}<0.05)$.

After adjustment for child's and household covariates, children exposed to HFIS compared with food-sufficient counterparts had a 2.12-fold (95\% CI 1.63 to 2.75 ) and 2.01-fold (95\% CI 1.64 to 2.46) higher odds of depression and anxiety, respectively (Model 1, table 2). After additional adjusting for parental or primary caregiver's mental and emotional health status, the associations were attenuated but remained significant; HFIS was associated with a 1.53-fold (95\% CI 1.15 to 2.03) and 1.48-fold (95\% CI 1.20 to 1.82 ) higher odds of depression and anxiety, respectively (Model 2, table 2). To test the robustness of findings, we conducted a sensitivity analysis excluding younger children aged 3-5 years who only contributed to $0.6 \%$ of depression and $3.4 \%$ of anxiety cases to the analytical sample; results were materially unchanged (online supplemental table 2). In another sensitivity analysis among children aged 10-17 years who had data available on BMI, results were slightly attenuated but remained significant between HFIS and childhood depression (adjusted OR (aOR): 1.44; 95\% CI 1.09 to 1.91 ) and anxiety (aOR: 1.38 ; $95 \%$ CI 1.09 to 1.76 ; online supplemental table 3), after additionally adjusting for child's obesity status.

Sex differences in the association of HFIS with childhood depression or anxiety appeared, with positive associations among girls (aOR (95\% CI): depression 1.69 (1.16 to 2.48 ); anxiety 1.78 (1.33 to 2.38$)$ ) but not boys (1.42 (0.98 to 2.08$)$; 1.32 (1.00 to 1.73 ); both P-forinteraction $<0.01$; figure 2 ). In age-stratified analysis, the association of HFIS with childhood depression did not vary between children aged 3-11 years (aOR 1.78; 95\% CI 1.02 to 3.11) compared with those aged 12-17 years (aOR 1.47; 95\% CI 1.09 to 1.98; P-for-interaction >0.15). The association of HFIS with childhood anxiety were similar between children aged 3-11 years (aOR 1.53; 95\% CI 1.13 to 2.06 ) and $12-17$ years (aOR 1.56 ; $95 \% \mathrm{Ci}$ 1.19 to 2.02; P-for-interaction $>0.15$; online supplemental table 4). No racial/ethnic differences were observed in the associations of HFIS with depression or anxiety (P-forinteraction $>0.15$; data not shown).

\section{DISCUSSION}

In this analysis of the 2016-2018 NSCH data, HFIS was independently associated with parent-reported physiciandiagnosed current depression and anxiety among children aged 3-17 years in the USA, even after adjusting for important covariates. Sex-specific analysis provides suggestive evidence that girls compared with boys exhibited slightly greater vulnerability to adverse mental health issues (ie, depression and anxiety) associated with HFIS. With the American Academy of Pediatrics recommendation for routine screening for HFIS in primary care settings, ${ }^{57}$ our findings suggest that children identified with HFIS may warrant monitoring and evaluation of mental health and possible intervention. On the other hand, children with anxiety or depression may warrant screening for HFIS to better understand the potential underpinnings to their impaired mental health.

We found that HFIS was positively associated with odds of depression and anxiety among children aged 3-17 in the USA, after adjusting for covariates. Our findings of positive associations between HFIS and childhood depression and anxiety were consistent with some ${ }^{13-171920}$ but not all ${ }^{18}$ of previous studies on HFIS and child mental health outcomes. Several cross-sectional, prospective cohort and case-control studies in the USA and Canada echoed that HFIS was positively associated with childhood mental health problems including psychosocial function, conduct problems, hyperactivity and aggression, ${ }^{13-1720}$ but few studies focused on childhood depression or anxiety. ${ }^{17-20}$ In a prospective Canadian cohort study, children from food-insecure families were more likely to experience depression or anxiety and hyperactivity or inattention; ${ }^{18}$ however, after controlling for covariates including immigrant status and parental depression, HFIS only remained to be associated with hyperactivity 






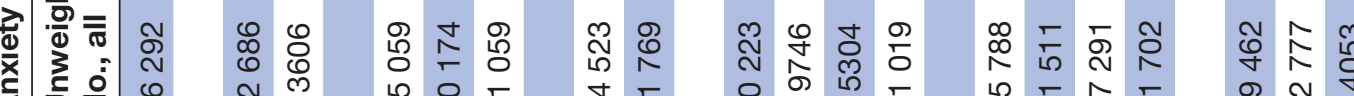

$+$

$\begin{array}{lll}\frac{1}{2} & \overline{0} & \overline{8} \\ \frac{0}{2} & 0 & 0 \\ 0 & 0\end{array}$

$\stackrel{10}{8}$

s.

$\overline{8}$
v
v

ơ

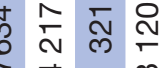
$\square \bar{m}$

ㅇำ

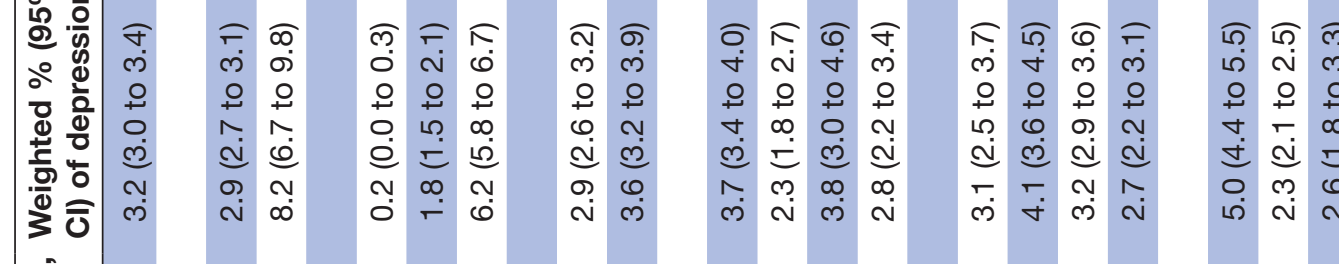

๑ $\widehat{\sigma} \widehat{\sigma}$

웅ㅇ

o

100

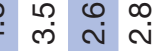

กิ

㝘

ल) 
or inattention but not depression or anxiety. ${ }^{18}$ Of note, inferences from these studies have been largely limited by restricted geographical and racial/ethnic variation, measurement of composite mental health outcomes including depression or anxiety but not focusing on these two conditions separately, and residual confounding due to missing data on covariates (eg, child's health insurance and parental mental and emotional health status). Our findings extend the literature by providing contemporary, racially/ethnically and socioeconomically diverse data on HFIS in relation to parent-reported physician-diagnosed current depression and anxiety among US children at a national level.

The mechanisms underlying the association between HFIS and childhood depression or anxiety remain to be elucidated. An experimental study in non-human primates revealed that nursing mothers exposed to unpredictable access to food had impaired interaction with their offspring, thus leading to a sense of insecurity characterised by anxiety and depression symptoms in their offspring. ${ }^{15}$ In human studies, children living in food-insecure/insufficient households may be conscious of the unstable food supply and even have to manage and allocate food resources. ${ }^{38}$ The experience of HFIS could be inherently destabilising and emotionally taxing for children, which could in turn develop into a toxic stress and escalate into mental health difficulties. ${ }^{38}$ Further, psychosocial stressors including HFIS early in life can influence mental health status by altering brain neurochemistry and morphology through brain neural circuits involving corticotropin-releasing factor, which has been hypothesised as a distinct biological subtype of adult depression. ${ }^{15}$ Moreover, living in a food-insecure/insufficient household may lead to nutritional deprivation in children, ${ }^{58-60}$ while nutrient deficiencies and poor dietary quality can potentially impair children's mental health. ${ }^{58} 5961$ Also importantly, psychosocial beyond biological factors such as parental mental health, parenting practices and bonding, social isolation, immigration status, inadequate child-care arrangements and lack of social support for the children may play important roles in the association between HFIS and childhood mental health. ${ }^{62}$

We observed significant sex differences, with associations between HFIS and current depression or anxiety being slightly more pronounced among girls compared with boys. Although the mechanisms underlying the sexspecific HFIS-depression association in children remain elusive, previous research in adults has illustrated plausible explanations. Biologically, compared with men, women are subject to greater fluctuations in reproductive hormones across lifespan, ${ }^{21}{ }^{22}$ and the changes in the hormones can alter brain structure and function and disproportionally induce anxiety and depression in women. ${ }^{21}$ Notably, these previous data are limited to adults and data on children are scant. Future investigations into the exact mechanisms underlying the sex disparities in the association of HFIS with childhood depression and anxiety are warranted. 


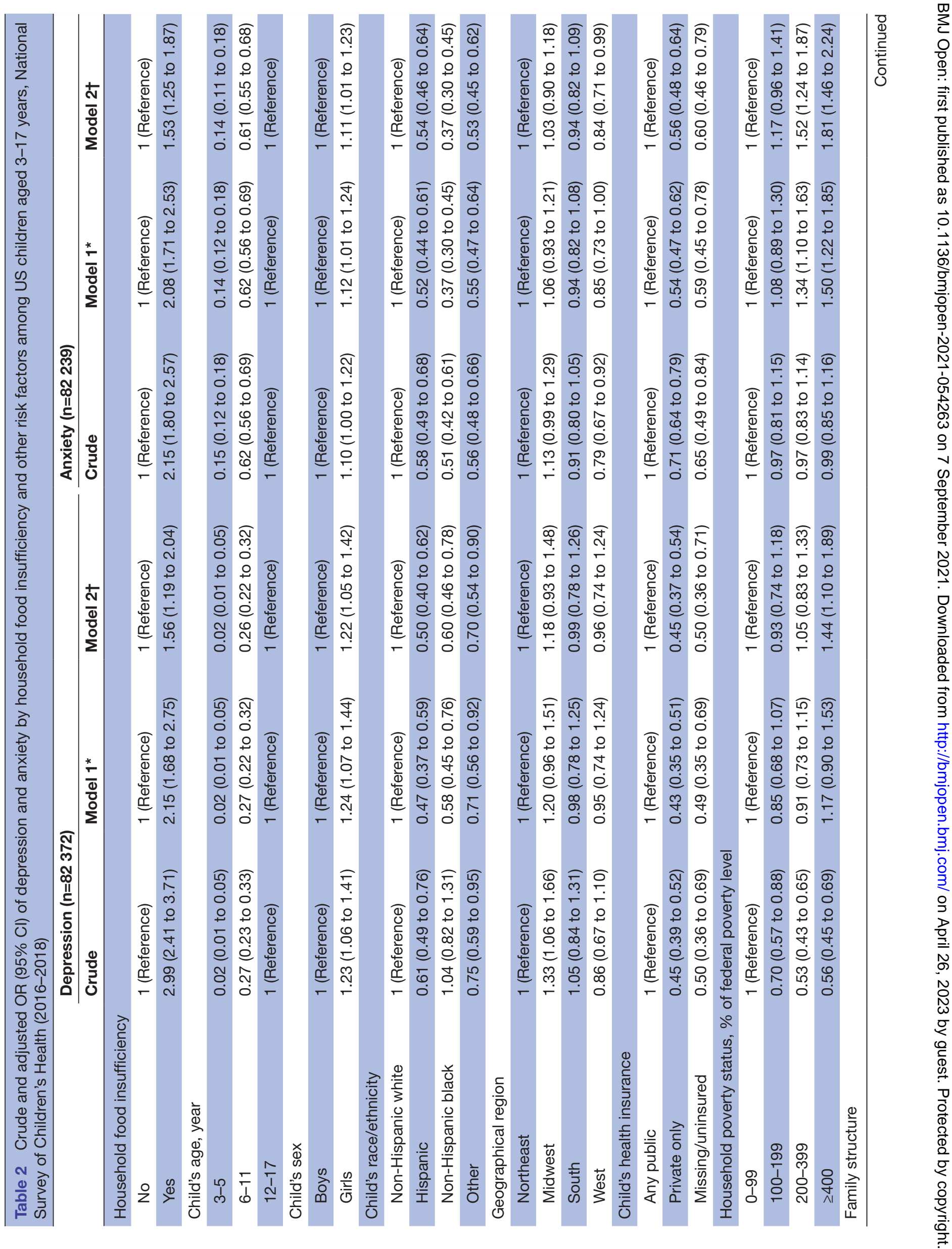



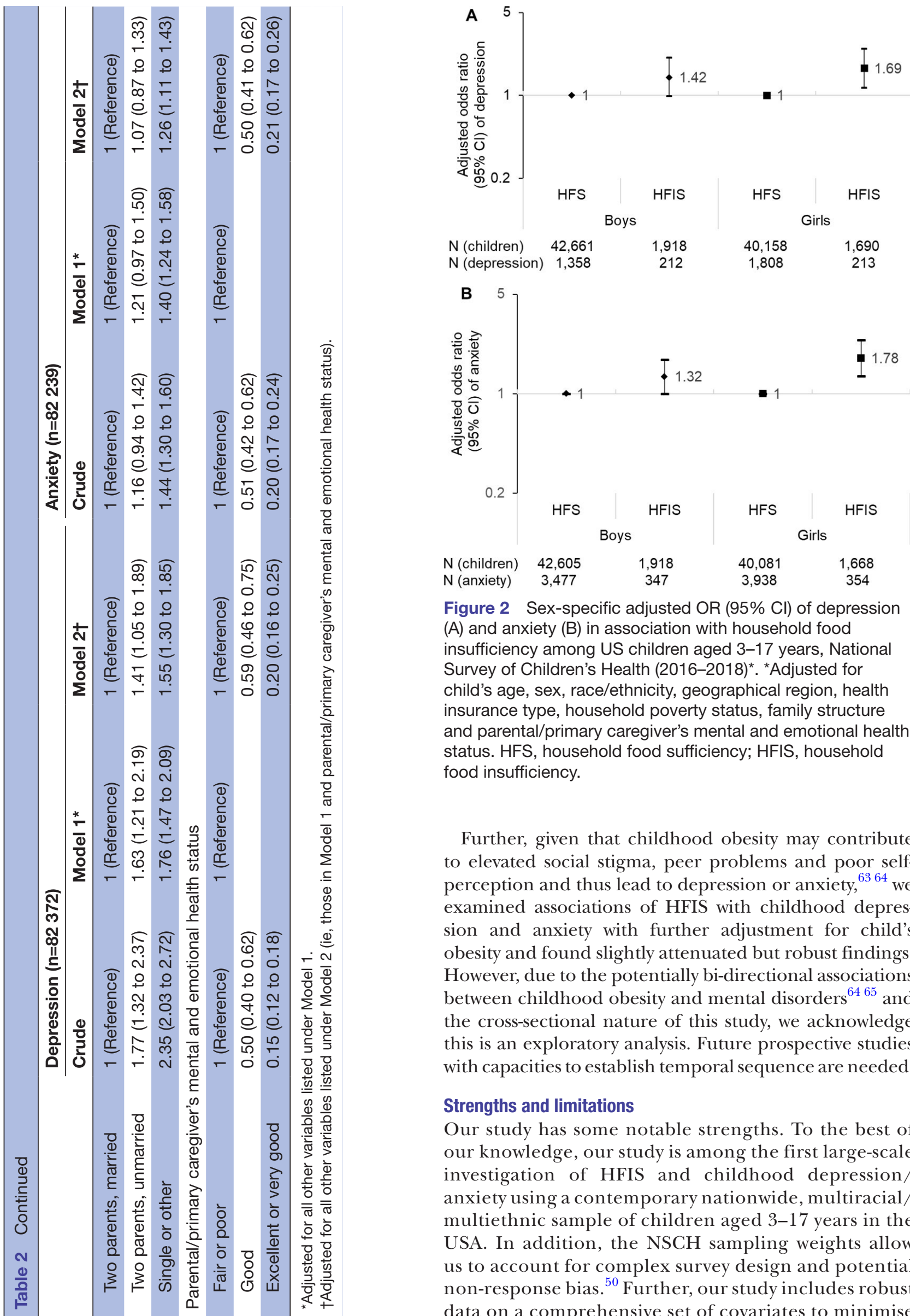

Figure 2 Sex-specific adjusted OR $(95 \% \mathrm{Cl})$ of depression (A) and anxiety (B) in association with household food insufficiency among US children aged 3-17 years, National Survey of Children's Health (2016-2018)*. *Adjusted for child's age, sex, race/ethnicity, geographical region, health insurance type, household poverty status, family structure and parental/primary caregiver's mental and emotional health status. HFS, household food sufficiency; HFIS, household food insufficiency.

Further, given that childhood obesity may contribute to elevated social stigma, peer problems and poor selfperception and thus lead to depression or anxiety, ${ }^{634}$ we examined associations of HFIS with childhood depression and anxiety with further adjustment for child's obesity and found slightly attenuated but robust findings. However, due to the potentially bi-directional associations between childhood obesity and mental disorders ${ }^{6465}$ and the cross-sectional nature of this study, we acknowledge this is an exploratory analysis. Future prospective studies with capacities to establish temporal sequence are needed.

\section{Strengths and limitations}

Our study has some notable strengths. To the best of our knowledge, our study is among the first large-scale investigation of HFIS and childhood depression/ anxiety using a contemporary nationwide, multiracial/ multiethnic sample of children aged 3-17 years in the USA. In addition, the NSCH sampling weights allow us to account for complex survey design and potential non-response bias. ${ }^{50}$ Further, our study includes robust data on a comprehensive set of covariates to minimise 
potential residual confounding. In particular, parents and children may have shared patterns of and predisposition to mental health issues ${ }^{66}{ }^{67}$ whereas limited previous studies accounted for parental mental health status. Our study served to address this issue and fill in the gap in the literature.

Our study has some limitations. The determination of childhood depression or anxiety status was based on parental report of physician diagnosis, which may be subject to potential recall and report bias. However, previous data suggest significant convergent and discriminant validity of parent-reported childhood depression and anxiety with child-report, teacher-report and peer-report measures ${ }^{68}$ Further, the weighted prevalence estimates of current depression $(3.2 \%)$ and anxiety $(7.4 \%)$ in this study were similar to the national prevalence (depression: $3.2 \%$ and anxiety: $7.1 \%$ ) among children aged $3-17$ years, ${ }^{69}$ supporting the potential external validity of the outcome. Additionally, our study used a single-item indicator for HFIS measurement, not the 18-item United States Department of Agriculture (USDA) Core Food Security Module. However, single-item indicators of HFIS have been validated and widely used as proxies for HFIS. ${ }^{42-44}$ Our study was based on a cross-sectional NSCH survey, without the ability to differentiate antecedents from endpoints and thereby infer causality between HFIS and childhood depression or anxiety, or rule out the possibility of reverse causation. ${ }^{41}$ Nonetheless, we tried to reduce the potential impact of reverse causation by adjusting for parental or primary caregiver's mental and emotional health status because children and their parents may have shared predisposition to mental dysfunctions and parental mental issues may impair their ability to ensure HFIS. Our analytical samples ( $\mathrm{n}=86427$ for depression and $\mathrm{n}=86292$ for anxiety) were drawn from the nationally representative NSCH study; however, those children who were excluded $(\mathrm{n}=2085$ or $\mathrm{n}=2220)$ were slightly more likely to be non-Hispanic black, single-parented, uninsured, have lower socioeconomic status and have parent/caregiver with impaired mental/emotional health, which may have either underestimated or overestimated the true effect sizes.

In conclusion, we report positive associations of HFIS with parent-reported physician diagnosis of current depression and anxiety among US children aged 3-17 years, independent of multiple covariates. Girls compared with boys exhibited a slightly greater vulnerability to depression and anxiety associated with HFIS. Our findings suggest that children identified as being exposed to HFIS may benefit from mental health evaluation and monitoring and possible intervention. Our findings also highlight the importance of promptly addressing HFIS with appropriate referral to resources such as Supplemental Nutrition Assistance Program, public child nutrition programmes and philanthropic food resources, which may help to alleviate the HFIS-related mental health outcomes in children. ${ }^{70}$ Meanwhile, children with anxiety or depression may be screened for HFIS to better contextualise their mental health issues. Further investigation is warranted in a prospective frame especially amid or post the COVID-19 pandemic as children may be more vulnerable than ever to a dual-threat of worsened HFIS and increased depression and anxiety. If our findings are confirmed in a prospective manner, efforts to reduce or eradicate HFIS targeting sociostructural causes are urgently warranted given its adverse impact on childhood mental health.

Acknowledgements We would like to thank all the participants and research team members in the National Survey of Children's Health surveys.

Contributors SZ conceptualised and designed the study, conducted statistical analysis, drafted the initial manuscript and revised the manuscript. ALN contributed to statistical analysis, conducted statistical review and reviewed and revised the manuscript. MRF, ALB, LL and AF critically reviewed the manuscript for important intellectual content. YZ conceptualised and designed the study, coordinated and supervised the study and critically reviewed the manuscript for important intellectual content. All authors contributed to data interpretation, editing and critical review of the manuscript and approved the final manuscript.

Funding This project was supported by the National Institute of Diabetes and Digestive and Kidney Diseases, grant K01DK120807 (Dr Zhu) and grant P30 DK092924 (Dr Ferrara), and Kaiser Permanente Northern California Community Benefits Program, grant RNG209983 (Dr Zhu).

Competing interests None declared.

Patient consent for publication Not required.

Ethics approval The National Center for Health Statistics Research Ethics Review Board approved all data collection procedures for the survey. The human subjects committee of the Kaiser Foundation Research Institute determined that the present study was exempt from Institutional Review Board review based on the use of de-identified data.

Provenance and peer review Not commissioned; externally peer reviewed.

Data availability statement Data are available in a public, open access repository. The datasets supporting the conclusions of this article are available in the National Survey of Children's Health Data Resource Center repository, [https://www. childhealthdata.org/learn-about-the-nsch/NSCH/data]

Supplemental material This content has been supplied by the author(s). It has not been vetted by BMJ Publishing Group Limited (BMJ) and may not have been peer-reviewed. Any opinions or recommendations discussed are solely those of the author(s) and are not endorsed by BMJ. BMJ disclaims all liability and responsibility arising from any reliance placed on the content. Where the content includes any translated material, BMJ does not warrant the accuracy and reliability of the translations (including but not limited to local regulations, clinical guidelines, terminology, drug names and drug dosages), and is not responsible for any error and/or omissions arising from translation and adaptation or otherwise.

Open access This is an open access article distributed in accordance with the Creative Commons Attribution Non Commercial (CC BY-NC 4.0) license, which permits others to distribute, remix, adapt, build upon this work non-commercially, and license their derivative works on different terms, provided the original work is properly cited, appropriate credit is given, any changes made indicated, and the use is non-commercial. See: http://creativecommons.org/licenses/by-nc/4.0/.

ORCID iD

Yeyi Zhu http://orcid.org/0000-0002-7296-738X

\section{REFERENCES}

1 Coleman-Jensen A, Rabbitt MP, Gregory CA. Household food security in the United States in 2018. US Department of Agriculture Economic Research Service - Economic Research Report 2019. 
2 Soni A. Statistical brief 472: top five most costly conditions among children, ages 0-17, 2012: estimates for the U.S. civilian Noninstitutionalized population. Medical Expenditure Panel Survey by Agency for Healthcare Research and Quality 2015:1-5 https://meps. ahrq.gov/data_files/publications/st472/stat472.shtml

3 Mojtabai R, Olfson M, Han B. National trends in the prevalence and treatment of depression in adolescents and young adults. Pediatrics 2016;138:e20161878.

4 Olfson M, Druss BG, Marcus SC. Trends in mental health care among children and adolescents. N Engl J Med Overseas Ed 2015;372:2029-38.

5 Twenge JM. Increases in depression, self-harm, and suicide among U.S. adolescents after 2012 and links to technology use: possible mechanisms. Psychiatr Res Clin Pract 2020;2:19-25.

6 Boorady R. Why childhood anxiety often goes undetected (and the consequences). Available: https://childmind.org/article/detectingchildhood-anxiety/ [Accessed 16 Jul 2020].

7 DiMaria L. The consequences of untreated depression in children. Available: https://www.verywellmind.com/possible-effects-ofdepression-in-children-1066622 [Accessed 16 Jul 2020].

8 The food insecurity experience scale: measuring food insecurity through people's experiences. Available: http://www.fao.org/3/ i7835e/i7835e.pdf

9 Larson NI, Story MT. Food insecurity and weight status among U.S. children and families: a review of the literature. Am J Prev Med 2011;40:166-73.

10 Zhu Y, Mangini LD, Hayward MD, et al. Food insecurity and the extremes of childhood weight: defining windows of vulnerability. Int $J$ Epidemiol 2020;49:519-27.

11 Mangini LD, Hayward MD, Zhu Y, et al. Timing of household food insecurity exposures and asthma in a cohort of US school-aged children. BMJ Open 2019;8:e021683.

12 Shankar P, Chung R, Frank DA. Association of food insecurity with children's behavioral, emotional, and academic outcomes: a systematic review. J Dev Behav Pediatr 2017;38:135-50.

13 Alaimo K, Olson CM, Frongillo EA. Food insufficiency and American school-aged children's cognitive, academic, and psychosocial development. Pediatrics 2001;108:44-53.

14 Poole-Di Salvo E, Silver EJ, Stein REK. Household Food Insecurity and Mental Health Problems Among Adolescents: What Do Parents Report? Acad Pediatr 2016:16:90-6.

15 Whitaker RC, Phillips SM, Orzol SM. Food insecurity and the risks of depression and anxiety in mothers and behavior problems in their preschool-aged children. Pediatrics 2006;118:e859-68.

16 McLaughlin KA, Green JG, Alegría M, et al. Food insecurity and mental disorders in a national sample of U.S. adolescents. J Am Acad Child Adolesc Psychiatry 2012;51:1293-303.

17 Maynard MS, Perlman CM, Kirkpatrick SI. Food insecurity and perceived anxiety among adolescents: an analysis of data from the 2009-2010 National health and nutrition examination survey (NHANES). J Hunger Environ Nutr 2019;14:339-51.

18 Melchior M, Chastang J-F, Falissard B, et al. Food insecurity and children's mental health: a prospective birth cohort study. PLoS One 2012; 7: e52615.

19 Leung CW, Epel ES, Willett WC, et al. Household food insecurity is positively associated with depression among low-income supplemental nutrition assistance program participants and incomeeligible nonparticipants. J Nutr 2015;145:622-7.

20 Mclntyre L, Williams JVA, Lavorato DH, et al. Depression and suicide ideation in late adolescence and early adulthood are an outcome of child hunger. J Affect Disord 2013;150:123-9.

21 Altemus M. Sex differences in depression and anxiety disorders: potential biological determinants. Horm Behav 2006;50:534-8.

22 Altemus M, Sarvaiya N, Neill Epperson C. Sex differences in anxiety and depression clinical perspectives. Front Neuroendocrinol 2014;35:320-30.

23 Flores G, Tomany-Korman SC. Racial and ethnic disparities in medical and dental health, access to care, and use of services in US children. Pediatrics 2008;121:e286-98.

24 Kaufman J, Martin A, King RA, et al. Are child-, adolescent-, and adult-onset depression one and the same disorder? Biol Psychiatry 2001;49:980-1001

25 Marrast L, Himmelstein DU, Woolhandler S. Racial and ethnic disparities in mental health care for children and young adults: a national study. Int J Health Serv 2016;46:810-24.

26 Nam Y, Huang J, Heflin C, et al. Racial and ethnic disparities in food insufficiency: evidence from a statewide probability sample. J Soc Social Work Res 2015;6:201-28.

27 Odoms-Young A, Bruce MA. Examining the impact of structural racism on food insecurity: implications for addressing racial/ethnic disparities. Fam Community Health 2018;41:S3.
28 Hake M, Engelhard E, Dewey A. The impact of the coronavirus on child food insecurity. Available: https://www.feedingamerica.org/ research/coronavirus-hunger-research [Accessed 4 Jul 2020].

29 Loades ME, Chatburn E, Higson-Sweeney N, et al. Rapid systematic review: the impact of social isolation and loneliness on the mental health of children and adolescents in the context of COVID-19. J Am Acade Child Adolesc Psych 2020;59:1218-39.

30 Patrick SW, Henkhaus LE, Zickafoose JS, et al. Well-Being of parents and children during the COVID-19 pandemic: a national survey. Pediatrics 2020;146:e2020016824.

31 Nagata JM, Ganson KT, Whittle HJ. Food insufficiency and mental health in the US during the COVID-19 pandemic. Am J Prevent Med 1921.

32 Council NR. Measuring food insecurity and hunger: phase 1 report. National Academies Press, 2005.

33 Jones AD, Ngure FM, Pelto G, et al. What are we assessing when we measure food security? A compendium and review of current metrics. Adv Nutr 2013;4:481-505.

34 United States Census Bureau. NSCH survey methodology. Available: https://www.childhealthdata.org/learn-about-the-nsch/methods [Accessed 20 Dec 2020]

35 United States Census Bureau. 2017 National Survey of Children's Health: methodology report. US Bureau of the Census Washington, DC. Available: https://www.census.gov/content/dam/Census/ programs-surveys/nsch/tech-documentation/methodology/2017NSCH-Methodology-Report.pdf [Accessed 15 Dec 2020].

362018 National survey of children's health: methodology report. Available: https://www2.census.gov/programs-surveys/nsch/ technical-documentation/methodology/2018-NSCH-MethodologyReport.pdf [Accessed 15 Aug 2020].

37 Child and Adolescent Health Measurement Initiative. Fast facts: 2017-2018 National survey of children's health. Available: https:// www.childhealthdata.org/learn-about-the-nsch/FAQ [Accessed 15 Jul 2020].

38 Jackson DB, Johnson KR, Vaughn MG. Household food insufficiency and children witnessing physical violence in the home: do family mental illness and substance misuse moderate the association? Matern Child Health J 2019;23:961-70.

39 Jackson DB, Chilton M, Johnson KR, et al. Adverse childhood experiences and household food insecurity: findings from the 2016 national survey of children's health. Am J Prev Med 2019;57:667-74.

40 Jackson DB, Johnson KR, Vaughn MG, et al. The role of neighborhoods in household food insufficiency: considering interactions between physical disorder, low social capital, violence, and perceptions of danger. Soc Sci Med 2019;221:58-67.

41 Balistreri KS. Food insufficiency and children with special healthcare needs. Public Health 2019;167:55-61.

42 Alaimo K, Briefel RR, Frongillo EA et al. Food insufficiency exists in the United States: results from the third National health and nutrition examination survey (NHANES III). Am J Public Health 1998:88:419-26.

43 Narain K, Bean-Mayberry B, Washington DL, et al. Access to care and health outcomes among women veterans using Veterans administration health care: association with food insufficiency. Womens Health Issues 2018;28:267-72.

44 Briefel RR, Woteki CE. Development of food sufficiency questions for the third National health and nutrition examination survey. $J$ Nutr Educ 1992;24:24S-8.

45 Hayes A. Federal poverty level (FPL). Available: https://www. investopedia.com/terms/f/fpl.asp [Accessed 26 Jul 2021].

46 Anderson SE, Cohen P, Naumova EN, et al. Adolescent obesity and risk for subsequent major depressive disorder and anxiety disorder: prospective evidence. Psychosom Med 2007;69:740-7.

47 Akinbami LJ, Ogden CL. Childhood overweight prevalence in the United States: the impact of parent-reported height and weight. Obesity 2009;17:1574-80.

48 Goodman E, Hinden BR, Khandelwal S. Accuracy of teen and parental reports of obesity and body mass index. Pediatrics 2000;106:52-8.

49 Mickey RM, Greenland S. The impact of confounder selection criteria on effect estimation. Am J Epidemiol 1989;129:125-37.

50 The United States Census Bureau, Associate Director of Demographic Programs, National Survey of Children's Health. 2016 National survey of children's health frequently asked questions. Available: https://www.census.gov/content/dam/Census/programssurveys/nsch/tech-documentation/methodology/NSCH\%202016\% 20FAQs.pdf [Accessed 15 Jul 2020].

51 U.S. Census Bureau. 2016 National survey of children's health data users frequently asked questions (FAQs). Available: https://www. census.gov/content/dam/Census/programs-surveys/nsch/tech- 
documentation/methodology/NSCH-2016-FAQs.pdf [Accessed 20 Jul 2020].

52 Lewis T. Analyzing categorical variables from complex survey data using proC SURVEYFREQ. Midwest SAS users group 2013 conference proceedings, Columbus, $\mathrm{OH} 2013$.

53 Vila G, Zipper E, Dabbas M, et al. Mental disorders in obese children and adolescents. Psychosom Med 2004;66:387-94.

54 Erermis S, Cetin N, Tamar M, et al. Is obesity a risk factor for psychopathology among adolescents? Pediatr Int 2004;46:296-301.

55 Csábi G, Tényi T, Molnár D. Depressive symptoms among obese children. Eat Weight Disord 2000;5:43-5.

56 Bradley RH, Houts R, Nader PR, et al. The relationship between body mass index and behavior in children. J Pediatr 2008;153:629-34.

57 Council on Community Pediatrics, Committee on Nutrition. Promoting food security for all children. Pediatrics 2015;136:e1431-8

58 Lozoff B, Jimenez E, Hagen J, et al. Poorer behavioral and developmental outcome more than 10 years after treatment for iron deficiency in infancy. Pediatrics 2000;105:E51.

59 Skalicky A, Meyers AF, Adams WG, et al. Child food insecurity and iron deficiency anemia in low-income infants and toddlers in the United States. Matern Child Health J 2006;10:177-85.

60 Hanson KL, Connor LM. Food insecurity and dietary quality in US adults and children: a systematic review. Am J Clin Nutr 2014;100:684-92.

61 Khalid S, Williams CM, Reynolds SA. Is there an association between diet and depression in children and adolescents? A systematic review. Br J Nutr 2016;116:2097-108.
62 Gundersen C, Ziliak JP. Childhood food insecurity in the U.S.: trends, causes, and policy options. Future Child 2014:24:1-19.

63 Pitrou I, Shojaei T, Wazana A, et al. Child overweight, associated psychopathology, and social functioning: a French school-based survey in 6- to 11-year-old children. Obesity 2010;18:809-17.

64 Puder JJ, Munsch S. Psychological correlates of childhood obesity. Int J Obes 2010;34:S37-43.

65 Goodman E, Whitaker RC. A prospective study of the role of depression in the development and persistence of adolescent obesity. Pediatrics 2002;110:497-504.

66 Biederman J, Faraone SV, Hirshfeld-Becker DR, et al. Patterns of psychopathology and dysfunction in high-risk children of parents with panic disorder and major depression. Am J Psychiatry 2001;158:49-57.

67 Stallard P, Norman P, Huline-Dickens S, et al. The effects of parental mental illness upon children: a descriptive study of the views of parents and children. Clin Child Psychol Psychiatry 2004;9:39-52.

68 Epkins CC, Meyers AW. Assessment of childhood depression, anxiety, and aggression: convergent and discriminant validity of self-, parent-, teacher-, and peer-report measures. J Pers Assess 1994:62:364-81.

69 Data and statistics on children's mental health. Available: https:// www.cdc.gov/childrensmentalhealth/data.html\#ref [Accessed 17 Sep 2020].

70 Frank DA, Bruce C, Ochoa E. Snap is medicine for food insecurity. Pediatrics 2020;146:e2020002105.

71 Hetrick RL, Rodrigo OD, Bocchini CE. Addressing PandemicIntensified food insecurity. Pediatrics 2020;146:e2020006924. 